\title{
EDUCAR O TRABALHADOR CIDADÃO PRODUTIVO OU O SER HUMANO EMANCIPADO?
}

\author{
TO EDUCATE THE PRODUCTIVE WORKER/CITIZEN \\ OR THE EMANCIPATED HUMAN BEING?
}

\author{
Gaudêncio Frigotto 1 \\ Maria Ciavatta 2
}

Resumo Este texto é parte da pesquisa "A Formação do Cidadão Produtivo" 3 , que tem por objetivo analisar as políticas de ensino médio técnico nos anos 80 , bem como as reformas educativas nos anos 90. Observa-se que muitas noções ou conceitos têm significado próprio nos embates da ideologia da globalização ou da mundialização do capital, mas podem ser resgatados em formas societárias alternativas, tais como trabalho e trabalhador produtivo, cidadania, cidadão produtivo e emancipação, se resgatados na sua historicidade. A idéia de cidadania, se a entendemos como parte de um projeto emancipador, apresenta alguns obstáculos em relação à democracia e ao trabalho na concepção liberal. Tanto no sentido liberal da cidadania como direitos civis, políticos e sociais do indivíduo, quanto no sentido marxiano de cidadania coletiva, o termo tem exigências que remetem, no Brasil, à forma histórica de inserção restrita dos cidadãos brasileiros na comunidade política. Distancia-se, também, das reformas educativas em curso no ensino médio técnico, com seus cursos breves modulares, com a redução do saber e da técnica às questões operacionais, aos valores pautados pelo individualismo e pela competitividade exigidos pelo mundo empresarial.

Palavras-chave cidadão produtivo; cidadania; emancipação; educação e trabalho; ensino médio técnico.
Abstract This text is part of the research entitled "The Education of the Productive Citizen" (A Formação do Cidadão Produtivo), the objective of which is to analyse the 1980 s' $^{\prime}$ policies on technical secondary teaching as well as the educational reforms that occurred in the 1990s. It is noted that, although many notions and concepts - such as work, productive worker, citizenship, productive citizen and emancipation - may have a specific meaning in the ideological debates on globalisation or on the 'mondialization du capital' they can be used in alternative societal forms if rescued in their historicity. The notion of citizenship, if we see it as part of an emancipating project, presents some obstacles in relation to democracy and to the liberal conception of work. Both in the liberal meaning of citizenship as an individual's civil, political and social rights, and in the Marxian meaning, as collective citizenship, the term involves certain demands that, in Brazil, were not fulfilled by the historically restrictive form of insertion of the Brazilian citizens into the political community. They are also far from being fulfilled by the present educational reforms in the technical secondary teaching with their short modular courses and a reduction of knowledge and of skills to mere operational issues, to values guided by individualism and by the competitiveness demanded by the business world. Key words productive citizen; citizenship; emancipation; education and work; technical secondary teaching. 


\section{Introdução}

As palavras ou vocábulos que usamos para nomear as coisas ou os fatos e acontecimentos não são inocentes. Buscam dar sentido ou significar estas coisas, estes fatos ou estes acontecimentos em consonância com interesses vinculados a determinados grupos, classes ou frações de classe. Mesmo os conceitos resultantes de um processo de elaboração sistemática e crítica ou científica não são, como querem os positivistas ou as visões metafísicas da realidade, imunes aos interesses em jogo nas diferentes ações e atividades que os seres humanos efetivam na produção de sua existência. É neste sentido que autores como Bakhtin (1981) e Gramsci (1978) assinalam que toda linguagem, mesmo a denominada científica, é ideológica 4 . Outra face da mesma problemática situa-se no fato de que, em determinadas épocas, certas palavras são focalizadas e afirmadas e outras silenciadas ou banidas. Isso também não é fortuito.

Esta compreensão nos indica que a atitude mais adequada a se adotar, tanto do ponto de vista da produção do conhecimento quanto da ação político-prática, é a de vigilância crítica, buscando desvendar o sentido e o significado das palavras e dos conceitos, bem como perceber o que nomeiam ou escondem e que interesses articulam. Esta vigilância necessita ser redobrada em períodos históricos em que os conflitos e as disputas se acirram. Declaramos ser este o caso do nosso tempo, não apenas porque a abundante literatura sobre o tema assim afirma, assinalando sua grave crise e profundas transformações econômicas, científicas, culturais e políticas, mas, também, por ser o tempo em que vivemos. Um tempo, como assinala Robin Blackburn (1992), em que como nunca "houve tanto fim", ou a "era dos extremos", como afirma Eric Hobsbawm (1995), referindo-se ao século XX.

Ocuparemo-nos aqui, da análise, inicialmente, de termos que, por vezes, se expressam como noções ou conceitos e que ganham força no contexto dos embates da ideologia da globalização, ou da mundialização do capital, e de formas societárias alternativas - trabalho e trabalhador produtivo, cidadania e cidadão produtivo e emancipação - buscando resgatá-los na sua historicidade e nos limites da concepção liberal burguesa. Como desdobramento, analisaremos como estes conceitos mais gerais se explicitam no campo educativo, mormente da educação profissional - configurando perspectivas de projetos alternativos, particularmente na realidade brasileira. Percebemos que, no Brasil, nos anos 90, praticamente desapareceram, nas reformas educativas efetivadas pelo atual governo, os vocábulos 'educação integral', 'omnilateral', 'laica', 'unitária', 'politécnica' ou 'tecnológica' e 'emancipado$\mathrm{ra}^{\prime}$, realçando-se o ideário da 'polivalência', da 'qualidade total', das 'competências', do 'cidadão produtivo' e da 'empregabilidade'. 


\section{A nova sociabilidade do capital e o "imperialismo simbólico"}

Diferentes autores chamam atenção para o fato de que as mudanças societárias que vivemos a partir das últimas décadas do século XX trazem, de forma insistente, um conjunto de vocábulos ou noções que, no entender de Bourdieu e Wacquant (2000), constituem uma espécie de "nova língua" e configuram uma espécie de vulgata aparentemente sem muito sentido. Estes autores fazem uma síntese ampla desta nova vulgata no contexto da nova (des)ordem mundial decorrente da mundialização do capital, da ideologia neoliberal e do pós-modernismo.

\footnotetext{
“Em todos os países avançados, patrões, altos funcionários internacionais, intelectuais de projeção na mídia e jornalistas de primeiro escalão se puseram em acordo em falar uma estranha novlangue cujo vocabulário, aparentemente sem origem, está em todas as bocas: 'globalização', 'flexibilidade', 'governabilidade', 'empregabilidade', 'underclass e exclusão'; nova economia e 'tolerância zero', 'comunitarismo', 'multiculturalismo' e seus primos pós-modernos, 'etnicidade', 'identidade', 'fragmentação' etc.. A difusão dessa nova vulgata planetária, da qual estão notavelmente ausentes capitalismo, classe, exploração, dominação, desigualdade, e tantos vocábulos decisivamente revogados sob o pretexto de obsolescência ou de presumida impertinência, é produto de um imperialismo apropriadamente simbólico: seus efeitos são tão mais poderosos e perniciosos porque ele é veiculado não apenas pelos partidários da revolução neoliberal que, sob a capa da 'modernização', entende reconstruir o mundo fazendo tábula rasa das conquistas sociais e econômicas resultantes de cem anos de lutas sociais, descritas, a partir dos novos tempos, como arcaísmos e obstáculos à nova ordem nascente, porém também por produtores culturais (pesquisadores, escritores, artistas) e militantes de esquerda que, em sua maioria, ainda se consideram progressistas" (Bourdieu e Wacquant, 2000, p. 1).
}

Luiz Fernando Veríssimo (2001), referindo-se à ideologia neoliberal na América Latina, mostra-nos como a classe dominante manipula a informação e deturpa conceitos, configurando um "inferno semântico". Noam Chomsky (2002), consagrado lingüista e hoje um dos mais importantes intelectuais críticos do capitalismo das mega-corporações, ao analisar o sentido histórico e humano do II Fórum Social Mundial - 2002, mostra como o termo globalização, que na tradição da $\mathrm{I}^{\mathrm{a}} \mathrm{e} \mathrm{II}^{\mathrm{a}}$ Internacionais Socialistas tem o sentido de internacionalismo, de solidariedade entre os seres humanos e de partilha dos bens do mundo, é apropriado pelos detentores do grande capital na perspectiva dos processos predatórios, em nome do lucro.

A nova vulgata a que se referem Bourdieu e Wacquant representa uma forte investida, no plano supra-estrutural, dos detentores do grande capital 
e do poder e indica a forma como se representam as relações sociais, econômicas, culturais e educativas. Trata-se de pautar a agenda do pensamento único, silenciando determinadas perspectivas analíticas e determinados conceitos e hipertrofiando outros. Com efeito, como sintetiza Galeano (2000), a partir do que leu escrito em uma parede em Quito: “Quando tínhamos todas as respostas, mudaram as perguntas".

Para desespero de milhões de seres humanos, muitos dos quais vivem no Brasil e necessitam de emprego, de casa, de saúde e educação pública, de cultura, lazer e aposentadoria digna, quem mudou as perguntas foram o conservadorismo ou os profetas do neoliberalismo.

\footnotetext{
“Algo muito profundo está ocorrendo quando a sociedade não se indaga Quais os caminhos para vencer o subdesenvolvimento e a desigualdade? Mas Como atrair capitais; quando a preocupação principal dos trabalhadores deixa de ser Como ampliar direitos? e se torna Como encontrar emprego? Quando reluzem em bancas de revista títulos tipo Com quem Madonna está saindo? Ou Que dieta pode salvar seu casamento?, e não mais Onde vai parar a revolução sexual?" (sic) (Le Monde Diplomatique, 2000, p. 1)
}

Esta mesma imprensa, com poderosas redes mundiais controladas por estas forças conservadoras substitui a milenar sentença de Protágoras de que o ser humano é "a medida de todas as coisas" pelo ideário de que o mercado é, agora, o parâmetro de tudo. Divulgam, aos quatro cantos do mundo, um vocábulo cujo epílogo é a precarização da vida das maiorias e a perda de direitos: “Ajuste estrutural. Austeridade. Corte de gastos públicos. Superávit primário. Privatização. Abertura comercial. Eficiência. Produtividade. Garantia aos investidores. Enxugamento. Terceirização. Flexibilização de direitos. Demissões"(Le Monde Diplomatique, op. cit.) No campo educacional, esse decálogo se expressa com os vocábulos como qualidade total, sociedade do conhecimento, educar por competência e para a competitividade, empregabilidade, cidadão ou trabalhador produtivo, etc.

Entendendo a linguagem como criadora de sentidos e significados mediatamente constitutivos da realidade histórica e apreendendo-a, portanto, vinculada às relações sociais de produção da existência humana, sublinhamos a importância política que assume o embate teórico de crítica às noções dominantes ou a destruição das perspectivas que Karel Kosik (1968) denomina de pseudoconcretas. O desafio mais complexo, para aqueles que se fundamentam no materialismo histórico, como indica Francisco de Oliveira (1987), é de saturar de historicidade os conceitos e as categorias analíticas. 


\section{Trabalho e trabalhador produtivo}

O debate sobre trabalho e trabalhador produtivo é tão velho quanto a própria história humana. Em última instância, trata-se de compreender como os seres humanos, na sua pré-história de sociedades classistas, como as definiu Marx, significaram e atribuíram valor às atividades de produção e reprodução de sua vida material e simbólica, intelectual ou espiritual. A idéia, ainda hoje forte, de que o trabalho do espírito ou o trabalho intelectual é superior ao trabalho material não é algo natural e eterno, mas é produto de determinadas relações sociais historicamente determinadas pelos seres humanos.

Com a emergência e afirmação do modo de produção capitalista, rompese, por necessidade intrínseca, com a escravidão e busca-se ressignificar o trabalho de sua conotação negativa de "tripalium"(castigo) para uma conotação positiva de "labor"5. Esta afirmação positiva engendra uma dupla força: de embate contra as relações sociais e de produção dos modos de produção pré-capitalistas, sobretudo o feudal; e de afirmação daquilo que é o nec plus ultra da forma especificamente capitalista de produção: extrair o máximo de trabalho não pago ou a mais-valia absoluta, relativa ou ambas combinadas.

Desde o início, os intelectuais encarregados de produzir o cimento ideológico na nova ordem social foram expressando a sua representação de trabalho e trabalhador produtivo e da própria concepção de produtividade. Não se trata, aqui, sobretudo, de uma maquinação maquiavélica, mas da visão de classe que engendram e expõem e cujo desfecho é a naturalização da sociedade de classes.

Marx, na análise das teorias da mais-valia, estabelece um longo debate crítico mostrando qual é a compreensão de produtividade e de trabalhador produtivo no pensamento dos fisiocratas, dos mercantilistas e dos teóricos do capitalismo: Smith, Ricardo, Sismondi6. Todos estes autores vão disseminar idéias vulgares ou parciais do que seja trabalho e trabalhador produtivo que, em última análise, encobrem o sentido forte e efetivo de produtividade e de trabalhador produtivo para o capital.

A luta da classe trabalhadora e de seus intelectuais ao longo de dois séculos do capitalismo foi buscar, sistematicamente, não só desmascarar o falseamento das noções de produtividade e de trabalhador produtivo, mas lograr conquistas importantes em termos de regulamentação do capital e de frear a superexploração. A regulamentação da jornada de trabalho é, sem dúvida, uma de suas conquistas fundamentais.

É compreensível que, no contexto da desregulamentação do capital, na nova (des)ordem mundial sob a égide da ideologia neoliberal, a vulgata da produtividade e das competências volte com grande peso. Cabe um sistemático embate para explicitar o significado deste novo senso comum. Neste em- 
bate, devem-se aprofundar os seguintes aspectos relacionados à produtividade e ao trabalho produtivo:

a) No sentido absoluto de produção de bens, valores de uso ou serviços, tanto no plano material como imaterial, toda atividade humana produz algo e, neste sentido, é produtiva. O agricultor que planta em seu pequeno lote de terra para gerar sua sobrevivência, a mulher ou homem que preparam alimento para si ou para outros, a dona de casa que cuida dos afazeres domésticos, entre outros, todos podem ser considerados produtivos. Podemos dizer, também, que, variando os meios utilizados, a tecnologia, etc., essas atividades podem ter maior ou menor produtividade. A maior produtividade decorre de obter, em um menor ou igual tempo e espaço de trabalho, mais produtos e de melhor qualidade. Improdutivo, seria, então, aquele que vive do ócio e não faz coisa alguma. Ou que, em relação aos produtivos, produz menos.

No senso comum e dentro da vulgata neoliberal, hoje, trabalho e trabalhador produtivos estão profundamente permeados pela idéia de que é aquele que faz, produz mais rapidamente, tem qualidade ou é mais competente. O fulcro central das visões apologéticas de produtividade e de trabalho produtivo resulta na idéia de que cada trabalhador é socialmente remunerado ou socialmente valorizado para manter-se empregado ou não, de acordo com sua produtividade, vale dizer, de acordo com a sua efetiva contribuição para a sociedade. Ou seja, o que o trabalhador ganha corresponde ao que contribui, e o que cada um tem em termos de riqueza depende de seu mérito, de seu esforço.

b) O trabalho produtivo e a produtividade do trabalho, no âmbito da produção capitalista, têm um sentido específico e, portanto, não podem ser tomados na sua dimensão absoluta de produção de valores de uso. O trabalho, sob o capitalismo, é transformado em força de trabalho despendida pelo trabalhador, mercadoria especial e única capaz de acrescentar ao valor produzido um valor excedente. Por isso, "trabalho produtivo no sentido da produção capitalista é o trabalho assalariado que, na troca pela parte variável do capital (a parte do capital despendida em salário), além de reproduzir essa parte do capital (ou o valor da própria força de trabalho), ainda produz mais-valia para o capitalista (...) A produtividade no sentido capitalista baseia-se na produtividade relativa; então, o trabalhador não só repõe um valor precedente, mas também cria um novo; materializa em seu produto mais tempo de trabalho materializado no produto que o mantém vivo como trabalhador. Dessa espécie de trabalho produtivo depende a existência do capital" (grifos nossos) (Marx, 1974, pp. 132-133).

Uma maior exploração pode dar-se mediante a extensão da jornada de trabalho, aumentando as horas de trabalho não pago ou de sobre-trabalho. Isto consubstancia a mais-valia absoluta. Há um aumento de produção de 
mercadorias ou serviços pela ampliação da jornada de trabalho. No início do capitalismo, vamos encontrar jornadas de trabalho de até 18 horas. Com a incorporação da ciência e da técnica, bem como com a criação de métodos e estratégias de gerência científica do trabalho, o capital acelera o ritmo do trabalho e da produção e, em menos tempo, produz mais mercadorias. Gera um aumento exponencial de produção de mercadorias e serviços pelo aumento da produtividade (intensidade) do trabalho. Isso consubstancia o que Marx denominou de mais-valia relativa.

Historicamente, observa-se que, dependendo do grau de desregulamentação do capital e da força ou fragilidade da classe trabalhadora, combinamse os processos geradores da mais-valia absoluta e relativa ao mesmo tempo. As estratégias neoliberais de desregulamentação e flexibilização das leis do trabalho, atualmente em curso no Brasil, são um exemplo emblemático de uma carta branca para o capital exercer uma super-exploração dos trabalhadores.

A apreensão atenta da sociabilidade do capital nos permite perceber que, após os anos 20 do século passado, ao mesmo tempo em que efetiva-se, pela luta dos trabalhadores e pelas contradições do próprio sistema capital, uma regulação mediante o fordismo, o keynesianismo e as políticas do Estado de Bem-Estar, instauram-se mecanismos de ruptura desta regulação. Com efeito, como nos mostra Chesnais (1996), a estratégia das multinacionais, hoje, a mundialização do capital, ideologicamente apresentada como globalização (Cardoso, 1999), representa um longo processo de recuperação do capital em mover-se sem barreiras e de tornar-se como nunca anticivilizatório e destruidor de direitos (Mészáros, 1996). O ideário de flexibilização, desregulamentação e descentralização, dentro deste ordenamento do capital, é um ex-post ou a expressão do imperialismo simbólico legitimador desta destruição e violência. Trata-se de uma cuidadosa elaboração super-estrutural e ideológica da forma de representar, falsear e cimentar a visão unidimensional do capital sobre a realidade econômica, psicossocial, política e cultural. O plano da dominação cultural, como mostra Jameson (2001), é atualmente o terreno mais fecundo desta disseminação ideológica.

No âmbito educacional, constatamos o surgimento da teoria do capital humano como explicação reducionista7 da não universalização das políticas regulatórias e do Estado de Bem-Estar, como indica Hobsbawm (1990 e 1995). Passa-se a idéia de que a desigualdade entre nações e indivíduos não se deve aos processos históricos de dominação e de relações de poder assimétricas e de relações de classe, mas ao diferencial de escolaridade e saúde da classe trabalhadora. Associam-se, de forma linear, a educação, o treinamento e a saúde à produtividade. A idéia de capital humano, nos termos do ideário capitalista, situa-se ainda no contexto das políticas keynesianas de desenvolvimento e de busca do pleno emprego. Mesmo nos marcos do ideário capita- 
lista, a educação é considerada um direito e uma estratégia de investimento do Estado.

O fim da idade de ouro do capitalismo e a nova 'era do mercado' e daquilo que assinalamos como o processo de mundialização do capital e monopólio privado pelas mega-corporações, do avanço da ciência e da tecnologia (Chomsky,1999) e de sua relação com o processo produtivo constituem uma materialidade de relações econômicas e sócio-culturais que demandam novas noções no plano simbólico e ideológico. Não se trata de afirmar a ocupação, a profissão e o emprego, mas sim de uma realidade desregulamentada e flexível. O ideário pedagógico vai afirmar as noções de polivalência, qualidade total, habilidades, competências 8 e empregabilidade do cidadão produtivo (um trabalhador que maximize a produtividade) sendo um cidadão mínimo.

\section{A cidadania e a formação do cidadão produtivo}

O Plano Nacional de Qualificação do Trabalhador - Planfor - consagrou o termo "formação do cidadão produtivo" segundo algumas diretrizes básicas (MTb, s.d.): consolidação da estabilidade econômica, desenvolvimento com equidade social, modernização das relações capital/trabalho, construção da cidadania, universalização da educação básica de qualidade, educação profissional contínua em vista da complementaridade entre a educação básica e a educação profissional, geração e melhor distribuição de renda em vista de mais e melhores empregos, e empregabilidade para o acesso e a permanência no mercado de trabalho.

Algumas destas diretrizes são, historicamente, bandeiras da esquerda no Brasil. No conjunto, são altamente ideologizadas em função do modelo econômico neoliberal, com primazia do mercado aberto ao capitalismo internacional, à privatização dos serviços básicos e à redução do papel do Estado, transferindo à sociedade civil a responsabilidade pelo bem-estar social sem a transferência devida dos recursos financeiros.

As estratégias definidas pelo PLANFOR também são bandeiras que a esquerda poderia assumir: negociação, participação, parceria, articulação, integração, descentralização. Poderia e, de fato, assumiram-nas sindicatos, Ongs, universidades, desenvolvendo projetos de educação profissional financiados pelo Fundo de Amparo ao Trabalhador (FAT), selecionados pelas Comissões Municipais ou Estaduais de Emprego e/ou pelas Secretarias de Trabalho e Desenvolvimento Social dos Estados ou pela própria Secretaria de Formação Profissional (SEFOR) do Ministério de Trabalho e Emprego ${ }^{9}$.

Mas, se, de um lado, essas estratégias e suas bandeiras sinalizam o fortalecimento da sociedade civil, de outro a ênfase na cidadania recai sobre o "cidadão produtivo" sujeito às exigências do mercado, onde o termo pro- 
dutivo refere-se ao trabalhador mais capaz de gerar mais-valia. O que significa submeter-se às exigências do capital que vão no sentido da subordinação e não da participação para o desenvolvimento de todas as suas potencialidades.

$\mathrm{Na}$ área acadêmica com inserção política, a utilização do termo cidadania é lugar comum nas reflexões que tratam das questões educacionais, principalmente a partir do final dos anos 70, quando o país ressurge da Ditadura para um movimento amplo de luta pelos direitos, de afirmação dos direitos da cidadania para todos os brasileiros. Entretanto, seu uso generalizado na produção acadêmica dos grupos progressistas, mesmo os filiados ao materialismo histórico, tem como quadro analítico o conceito de origem liberal de cidadania individual, que compreende os direitos civis, os políticos e os sociais (Marshall, 1967) ${ }^{10}$.

Mas o conceito de cidadania parece um conceito pouco elaborado entre nós. Não apenas por carência de reflexão, mas porque a própria questão da cidadania é, originalmente, uma questão alheia à constituição da sociedade brasileira pós-colonial, situação que teria se prolongado sob o fenômeno da exclusão dos "cidadãos" brasileiros de diversas instâncias da vida social. A questão subjacente é sobre quem pertence à comunidade política e, por extensão, quem são os cidadãos e quais são os seus direitos de brasileiros.

Devemos remontar brevemente à história do nascimento da nação brasileira após a ruptura com o império colonial. Para Santos (1978, pp. 78-80), os anos de 1822 a 1841 foram cruciais para a definição do tipo de sociedade que seria o Brasil. Para os liberais que conspiraram contra o regime colonial, o poder imperial deveria ser diminuído e a sociedade brasileira deveria governar o país. $\mathrm{O}$ que significava responder a várias questões: de onde emanava a fonte do poder político legítimo; se este deveria repousar sobre o centro de poder ou se o poder deveria ser delegado mediante mecanismos de representação política e social; quem estava qualificado para estas funções; quem pertencia à comunidade política como cidadão político pleno; para que serviam o governo e o Estado.

Não obstante o conhecimento do pensamento liberal (Locke, Montesquieu e a versão americana do liberalismo), o pensamento que prevaleceu afastou-se do ideário liberal. No pacto constitucional apoiado pela elite brasileira, estabeleceu-se que o poder imperial antecedia a criação da sociedade. O Príncipe que rompeu a subordinação colonial tinha autonomia em relação ao pacto constitucional, à sociedade brasileira e à representação política. Nenhum dos poderes da comunidade política, o Legislativo, o Judiciário e o Executivo, poderiam ultrapassar o poder imperial, cuja função era exprimir a vontade do povo. O Imperador era o Poder Moderador e todos os ministros respondiam perante ele e não perante a comunidade política.

A questão sobre quem pertencia à comunidade política e, por extensão, nos termos atuais, quem era cidadão, recebeu interpretações ao longo do tempo. A primeira interpretação excluía da comunidade política somente os 
criminosos, os estrangeiros e os religiosos. Mas, como o pacto político deveria expressar as igualdades e desigualdades existentes na sociedade que, no pensamento da época, eram naturais, definiu-se que os homens de posses eram os responsáveis pela riqueza do país e constituíam a comunidade política, o que se traduziu pelo critério censitário de renda para distribuição dos direitos de voto.

Este artifício ideológico era, também, legitimado pelo pensamento liberal, para o qual o objetivo do governo seria proteger a vida, a liberdade e a propriedade dos cidadãos. Se a constituição de 1824 inaugurava a nação brasileira e considerava todos os homens cidadãos livres e iguais, também garantia a todos o direito à propriedade, inclusive escravos. Este seria outro grande limite do pensamento liberal e sobre quem pertencia à comunidade política.

A supressão progressiva da escravidão (1850 - Proibição do tráfico negreiro, 1865 - Lei dos Sexagenários, 1871 - Lei do Ventre Livre) não dirimiu a contradição entre cidadania e propriedade escravista.

“A manutenção da escravidão e a restrição legal do gozo pleno dos direitos civis e políticos aos libertos tornavam o que hoje identificamos como "discriminação racial" uma questão crucial na vida de amplas camadas das populações urbanas e rurais do período. Apesar da igualdade de direitos civis entre os cidadãos brasileiros reconhecidos pela Constituição, os cidadãos não-brancos continuavam a ter mesmo o seu direito de ir e vir dramaticamente dependente do reconhecimento costumeiro de sua condição de liberdade" (Mattos, 2000).

É com o duplo paradoxo "Na República que não era, a cidade não tinha cidadãos" que José Murilo de Carvalho (1987, p. 162) assinala a "castração política" da cidade do Rio de Janeiro, impedindo seu autogoverno e reprimindo a mobilização política de sua população urbana. O interesse das elites se apresenta como o interesse de toda a sociedade, e se instaura um novo sistema político sem que se alterem substancialmente as condições de vida precárias da população. Regimes ditatoriais, autoritarismo e repressão, paternalismo e clientelismo alimentam a subalternidade e o atraso social, conduzindo a uma "modernização conservadora" (Ciavatta, 2000, p. 77).

Este breve histórico nos permite visualizar a complexidade negativa do estabelecimento de uma comunidade política no Brasil que se pautasse, ao menos, pelo pensamento liberal, assegurando efetivamente os direitos da cidadania brasileira. Assim, se as categorias apresentadas por Marshall não correspondem exatamente aos fundamentos da utopia socialista da emancipação de todos os homens, elas são, ainda hoje, um instrumento útil para a compreensão dos limites históricos da cidadania no Brasil.

Marshall trabalha com os direitos individuais. Os primeiros a serem conquistados foram os direitos civis, que são os direitos à integridade física, à 
liberdade de ir e vir e de palavra. Historicamente, a estes seguem-se os direitos políticos, o direito de votar e ser votado. Seriam os direitos sociais, o direito aos benefícios da riqueza social (habitação, saúde, educação, etc.) os mais tardios a serem conquistados no mundo ocidental.

Entendemos que, no Brasil, embora, formalmente, todos sejamos cidadãos, há níveis e situações concretas diferenciadas de cidadania de acordo com as classes sociais. O que significa, efetivamente, acesso diferenciado aos bens necessários à sobrevivência, criando a situação de escândalo público (impune) dos indicadores de renda, traduzidos em pobreza e misérial1. O pertencimento formal à sociedade política não assegura direitos iguais para todos porque prevalece, na prática, o princípio lockeano do direito à propriedade. Prevalece "a idéia liberal de que o governo não deveria violar os direitos econômicos do cidadão, privadamente definidos" (Santos, op. cit., p. 79), e a idéia da primazia do mercado, de que nenhuma lei impeça seu livre funcionamento, conforme teorizada por Adam Smith.

A realidade dos fatos expõe a fragilidade das bases do conceito. Esta é a cidadania individual à qual Gohn se refere ao distingui-la da cidadania coletiva. Em ambas, duas dimensões são fundamentais, a liberdade e a igualdade. "A cidadania individual pressupõe a liberdade e a autonomia dos indivíduos num sistema de mercado, de livre jogo da competição, em que todos sejam respeitados e tenham garantias mínimas para a livre manifestação de suas opiniões - basicamente pelo voto - e da autorealização de suas potencialidades" (Gohn, 1995, p. 195). Supõe também um árbitro mediador, o Estado, o poder público.

A cidadania coletiva teria como referência, primeiro, a idéia de cidadão da polis grega e as virtudes cívicas que os cidadãos exercitam na comunidade onde vivem. A segunda referência seriam os movimentos sociais da atualidade e a busca de leis e direitos para categorias sociais historicamente excluídas da sociedade, lutas pela terra na cidade, nas favelas e no campo; e as lutas de certas camadas sociais, como as mulheres, as minorias étnicas, os homossexuais, etc. "Assim, a cidadania coletiva privilegia a dimensão sóciocultural, reivindicando direitos sob a forma da concessão de bens e serviços, e não apenas a inscrição desses direitos em lei; reivindica espaços sóciopolíticos", mantendo sua identidade cultural (Gohn, op. cit., p. 196).

Trein recupera o sentido de cidadania coletiva em Marx para fins de superação da cidadania burguesa. Como crítico do capitalismo e do liberalismo, Marx argumenta sobre as inconsistências do projeto liberal burguês na sociedade ocidental e da realidade prático-teórica que impede a emancipação completa do ser humano e limita o exercício da liberdade "que o mantém preso à idéia liberal de que é livre quem em sua vontade não está submetido a interferências e coerções" (Trein, 1994, pp. 126-127).

A emancipação se daria em dois momentos: o genético e o conjuntural. Quanto ao genético, a pergunta fundamental é sobre que espécie de eman- 
cipação está em questão. Com isso, Marx busca superar a perspectiva liberal burguesa de emancipação política posta pela Revolução Francesa para situá-la em outro nível.

Com a Revolução Francesa, alterou-se a forma de participação no poder político. Se, no feudalismo, a participação política de cada um era proporcional à sua participação social, ou seja, à apropriação da riqueza material e cultural e, necessariamente, desigual, com a Revolução Francesa os assuntos do Estado são assumidos como se fossem o interesse do povo e a vontade dos cidadãos. A emancipação política constituiu-se em emancipação da sociedade civil em relação à política.

Diferente do que supunha Rousseau, a participação de direito de todos os cidadãos na sociedade política não garante a igualdade e a liberdade contra os interesses particulares que visam o interesse próprio. A emancipação política torna-se a garantia das desigualdades existentes na sociedade civil, que é entendida como desigualdade da ordem natural. Diz Marx (1991, p. 50): “O homem não se libertou da religião, ele obteve a liberdade religiosa. Ele não se libertou da propriedade. Ele obteve a liberdade de propriedade. Ele não se libertou do egoísmo do ofício, ele obteve a liberdade de ofício".

No mesmo sentido, os direitos humanos se originam em direitos particulares do indivíduo, dissociado de sua comunidade. O direito humano à propriedade privada é o direito de desfrutar de seu patrimônio "sem atender aos demais homens, independentemente da sociedade, é o direito do interesse pessoal" (Marx, op.cit., p. 43).

No pensamento marxiano, o conceito de cidadania tem uma complexidade maior e está ligado ao coletivo ao qual o homem pertence:

\footnotetext{
"Somente quando o homem individual real recupera em si o cidadão abstrato e se converte, como homem individual, em ser genérico, em seu trabalho individual e em suas relações individuais; somente quando o homem tenha reconhecido e organizado suas "próprias forças" como forças sociais e quando, portanto, já não separa de si a força social sob a forma de força política, somente então se processa a emancipação humana" (Marx, op. cit., p. 52, grifos do autor).
}

Trein (op.cit., pp. 133-137) observa que, na sociedade atual, apesar da crise econômica e política e seus graves desdobramentos sociais (fala de 1994 com absoluta atualidade para o presente), há um alargamento dos espaços de atuação das classes sociais na sociedade civil para além da sociedade política. De outra parte, as características de uma sociedade complexa, onde a dinâmica social leva os indivíduos a participar de diferentes esferas da sociedade, lhes exige uma 'competência' particular para que a própria cidadania possa ser exercida. Esta diz respeito à capacidade do homem de, enquanto indivíduo real, recuperar em si o universal, o cidadão abstrato, a relação en- 
tre ele e o todo, a sociedade, em uma condição de 'co-pertencimento' à sua condição de indivíduo e de cidadão.

\section{Considerações finais}

Vivemos tempos difíceis, em que a nova sociabilidade do capital, ao mesmo tempo que aprofunda as desigualdades reais de trabalho e de condições de vida, dissemina uma nova semântica da qual estão notavelmente ausentes termos como 'capitalismo', 'classe', 'exploração', 'dominação', 'desigualdade'. E o faz com o apoio muitos intelectuais, de tecnologias mercadológicas e de poderosos meios de comunicação.

A "competência" para a cidadania, se a entendemos como parte de um projeto emancipador, apresenta, de modo especial, alguns obstáculos apontados por Bobbio (apud Trein, op. cit.) em relação à democracia e em relação ao trabalho. Em primeiro lugar, as condições de atendimento na democracia são cada vez mais restritas pela existência da distância gerada pelas grandes organizações, aumento da tecnoburocracia e de seu poder para tolher o atendimento aos direitos e restrições à participação de muitos. Quanto ao trabalho, à medida que crescem os bens materiais, as relações de trabalho se tornam mais complexas e exigem competências técnicas e políticas. Paralelamente, assistimos à desregulamentação acelerada da legislação laboral e à perda dos direitos pelos quais os trabalhadores lutaram durante todo o século XX.

A idéia de cidadania coletiva implica o resgate da individualidade como parte de um coletivo e, portanto, como sujeito político. Cabe observar o quanto a concepção de cidadania coletiva está distante da noção mercantil de cidadão produtivo. Este deve possuir as qualidades para a inserção em uma economia de mercado que o aliena de sua generalidade em comunhão política com os demais homens, para submetê-lo aos ditames da produtividade exigida pela reprodução do capital.

A concepção de Marx sobre trabalho produtivo é clara nas suas duas referências: à produção de valores de uso e à extração de um valor excedente ao valor do trabalho remunerado pelo capital. Permite-nos entender que o senso comum, que se apropria dos termos trabalho produtivo e cidadão produtivo com o sentido de produtor de valor de uso está, historicamente, contaminado pela idéia da produtividade do trabalho segundo os padrões do capitalismo.

O conceito de educação do homem integrado às forças sociais difere da mera submissão às forças produtivas. Esta concepção distancia-se dos cursos breves de educação profissional - a exemplo do PLANFOR- descontextualizados de uma política de desenvolvimento, geradora de trabalho, emprego e renda e de políticas sociais que sinalizem a melhoria de vida da população 
e a mudança de rumo na falta de perspectiva para os jovens e adultos desempregados. Distancia-se, também, das reformas educativas em curso no ensino médio técnico, com seus cursos breves modulares, com a redução do saber e da técnica às questões operacionais, dos valores pautados pelo individualismo e a pela competitividade exigidos pelo mundo empresarial. A educação do cidadão produtivo, onde o mercado funciona como princípio organizador do conjunto da vida coletiva, distancia-se dos projetos do ser humano emancipado para o exercício de uma humanidade solidária e a construção de projetos sociais alternativos.

\section{Notas}

1 Doutor em Educação pela PUC-São Paulo, Professor Titular em Economia Política da Educação na Faculdade de Educação da Universidade Federal Fluminense, Campus do Gragoatá, Niterói, RJ. <frigotto@uol.com.br>

2 Doutora em Educação pela PUC-RJ.Professora Titular em Trabalho e Educação na Faculdade de Educação da Universidade Federal Fluminense, Campus do Gragoatá, Niterói, RJ. <ciavatta@alternex.com.br>

3 Agradecemos a leitura e discussão do texto preliminar deste trabalho aos colegas e orientandos participantes do Projeto Integrado "A formação do cidadão produtivo - Da política de expansão do ensino médio técnico nos anos 80 à política da fragmentação da educação profissional nos anos 90; entre discursos e imagens" (Programa de Pós-graduação em Educação - Mestrado e Doutorado, UFF, Niterói), e aos participantes do Seminário promovido pela Superintendência de Formação Profissional (SUEPRO) do Estado do Rio Grande do Sul, durante o I I Fórum Social Mundial (Porto Alegre, março, 2002).

4 A ideologia é aqui tomada não simplesmente como falsa consciência, mas como uma concepção ou visão de mundo. Ver a este respeito: Gramsci (1978), Bakhtin (1981) e Lowy (1990).

5 Ver a esse respeito a análise empreendida por Nosella (1987).

6 Ver Marx (1974), Rosdolsky (2001) e Napoleoni (1981).

7 Ver a esse respeito Frigotto (1997, 2000 e 2002).

8 Sobre a pedagogia das competências, ver Ramos (2001).

9 Sobre a avaliação dos primeiros anos do PLANFOR, ver Lima Neto, 1999 e Ciavatta, 2000. 
10 Marlene Ribeiro realiza um cuidadoso retrospecto da origem do termo cidadania nos clássicos da filosofia política e considera que "um conceito delimitado histórica e socialmente pelas camadas proprietárias seja muito restrito para abarcar as questões de gênero, de raça, de etnia, de classe social que deverão estar incluídas em um projeto que se pretenda emancipante das, pelas e para as camadas subalternas" (2001, p. 78). É nosso ponto de vista que, em função se sua origem histórica, muitas outras palavras seriam impróprias para servir aos sujeitos de um projeto libertador, tais como educação, escola e tantas mais. Entendemos que não se deva banir as palavras porque elas fazem parte da memória que permite resgatar o passado e projetar o futuro. As palavras devem ser historicizadas na sua compreensão, e mostrados os seus limites, como faz a autora. Mas julgamos que elas devem também ser ressignificadas segundo projetos alternativos emancipadores.

11 Os $20 \%$ mais ricos da população detêm $64,1 \%$ da renda nacional, enquanto que os $64,1 \%$ mais pobres detêm o equivalente a 2,2\%, conforme o Informe de Desenvolvimento Mundial 2002 (O Globo, Rio de Janeiro, segunda-feira, 22 de abril de 2002, p. 15).

\section{Referências}

BAKHTIN, Mikhail.1997. Marxismo e filosofia da linguagem. São Paulo: Hucitec.

BLACKBURN, Robin.1992. Depois da queda. o fracasso do comunismo e o futuro do socialismo. Rio de Janeiro: Paz e Terra.

BOURDIEU, Pierre \& WACQUANT, Loic. 2001. A nova bíblia do Tio Sam. In: CATTANI, Alfredo (org.) Fórum Social Mundial - A construção de um mundo melhor. Petrópolis: Editora Vozes e outras, pp. 156-171.

CARDOSO, Miriam L. 1999. A ideologia da globalização e descaminhos da Ciência Social. In: GENTILI, Pablo (org.) Globalização Excludente - desigualdade, exclusão e democracia na nova ordem mundial. Petrópolis: Vozes.

CHESNAIS, François.1996. Mundialização do capital. São Paulo: Scrita.

CHOMSKY, Noam.1999. A luta de classes. Porto Alegre: Artes Médicas.

_. 2002. Entrevista à Rede Globo de Televisão. Canal Globo News em 28.01.2002.

CIAVATTA, Maria.2000. A educação profissional do cidadão produtivo à luz de uma análise de contexto. Proposta, 29 (86):76-89.
FRIGOTTO, Gaudêncio.1997. Delírios da razão: crise do capital e metamorfose conceitual no campo educacional.In: GENTILI, Pablo (org). A pedagogia da exclusão. Rio de Janeiro: Vozes, pp. 77-108 2000. A educação e a crise do capitalismo real. 4a ed. São Paulo: Cortez, 2002. A Produtividade da escola improdutiva. 7a ed. São Paulo: Cortez, .

GALEANO, Eduardo.2001. Quando tínhamos todas as respostas mudaram as perguntas. Le Monde Diplomatique, Paris, p. 1.

GOHN, Maria da Glória.1995. História dos movimentos sociais e lutas sociais: a construção da cidadania dos brasileiros. São Paulo: Loyola.

GRAMSCI, Antonio.1978. A concepção dialética da história. Rio de Janeiro: Civilização Brasileira.

HOBSBAWM, Eric.1995. A era dos extremos. São Paulo: Companhia das Letras. . 1990. Nações e nacionalismos desde 1760. Rio de Janeiro: Paz e Terra.

JAMESON, Fredric.2001. A cultura do dinheiro. Petrópolis: Vozes.

KOSIK, Karel.1968. A dialética do concreto. Rio de Janeiro: Paz e Terra. 
LE MONDE DIPLOMATIQUE. 2000. Caderno Especial, Paris, setembro de 2000, p.1. LOWY, Michel.1990. As aventuras de Karl Marx contra o Barão de Münchausen. São Paulo: Busca Vida.

MARSHALL, Thomas H. 1967. Cidadania, classe social e status. Rio de Janeiro: Zahar.

MARX, Karl. 1980. Teorias da mais-valia. Livro 4 de $O$ Capital, Vol. I. Rio de Janeiro: Civilização Brasileira.

. 1991. A questão judaica. 2a ed.São Paulo: Moraes.

1974. Capítulo VI Inédito de O Capital. Resultados do processo de produção imediata. São Paulo: Moraes.

MATTOS, Hebe M. 2000. Escravidão e cidadania no Brasil monárquico. Rio de Janeiro: Jorge Zahar.

MÉSZÁROS, Istvan. 1996. Beyond capital: towards a theory of transition. Monthly Review, London: Merlin Press.

MTb (Ministério do Trabalho). (s/d). Educação Profissional. PLANFOR. Formando o cidadão produtivo. Brasília: $\mathrm{MTb} /$ SEFOR.

NAPOLEONI, Cláudio. 1982. O futuro do capitalismo. Rio de Janeiro: Graal.

NOSELLA, Paulo. 1987. Trabalho e educação. In: Frigotto, Gaudêncio (org). Tra- balho e conhecimento: dilemas na educação do trabalhador. São Paulo: Cortez.

OLIVEIRA, Francisco. 1987. O elo perdido. Classe e identidade de classe. São Paulo: Brasiliense.

RAMOS, Marise N. 2001. A pedagogia das competências: autonomia ou adaptação? São Paulo: Cortez.

RIBEIRO, Marlene. 2001. Cidadania: interrogações ao conceito para a compreensão dos movimentos sociais. Caderno de Debates no. 2, Centro de Assessoria Multiprofissional, Porto Alegre, p. 43-82.

ROSDOLSKY, Roman. 2001. Gênese e estrutura de O Capital. Rio de Janeiro: Ed. Universidade do Estado do Rio de Janeiro/Contraponto.

SANTOS, Wanderley Guilherme dos. 1978. Ordem burguesa e liberalismo politico. São Paulo: Duas Cidades.

TREIN, Eunice S. 1994. Trabalho, cidadania e educação: entre o projeto e a realidade concreta, a responsabilidade do empenho político. Tese de Doutorado em Educação, Rio de Janeiro: Faculdade de Educação, Universidade Federal do Rio de Janeiro.

VERÍSSIMO, Luiz Fernando. 2001. Ideologias (II). O Globo, 14 abr. Caderno Opinião, p. 7. 